\title{
$\checkmark$ Physical activity in the UK: corross a unique crossroad?
}

\author{
Richard Weiler, ${ }^{1,2}$ Emmanuel Stamatakis $^{3}$
}

\section{INTRODUCTION}

Recent objective evidence from England and the USA suggests that low physical activity is the most prevalent chronic disease risk factor, with $95 \%$ of the adult population not meeting the modest physical activity guidelines. ${ }^{12}$ In the UK, the annual cost of physical inactivity has been estimated at $£ 8.2$ billion, whereas the annual cost of smoking has been estimated at $£ 1.5$ billion, ${ }^{3}$ alcohol at $£ 3.0$ billion $^{4}$ and obesity at $£ 4.2$ billion. ${ }^{1}$

However, despite this enormous burden on our public health and finances, the relative importance of physical inactivity as a primary cause of many chronic diseases is largely neglected within modern medicine and by health strategy. Surrogate risk factors for disease, such as hypertension, type II diabetes, obesity and dyslipidaemia, receive ample attention in medical education, have incentivised interventions embedded within primary care and are routinely reviewed during visits to a general practitioner (GP). Yet, despite physical inactivity being the most prevalent modifiable affliction and possibly the greatest chronic disease risk factor, ${ }^{5}$ it is still not receiving the attention that scientific and clinical evidence would seem to merit.

\section{PRIMARY CARE OPPORTUNITIES}

There is a unique structure to general practice and primary care within the UK National Health Service (NHS). UK GPs, who are usually the first point of contact for patients, have a unique position and opportunity to combat physical inactivity and its numerous associated comorbidities. Through the Quality and Outcomes Framework (QOF), GPs are financially rewarded for achieving healthcare targets. Setting up a new QOF point is relatively very cheap, costing approximately

\footnotetext{
${ }^{1}$ Specialist Registrar in Sport and Exercise Medicine, Imperial College Healthcare NHS Trust, Charing Cross Hospital, London, UK

${ }^{2}$ Locum General Practitioner, Hertfordshire, UK ${ }^{3}$ Department of Epidemiology and Public Health, University College London, London, UK
}

Correspondence to Dr Richard Weiler, Imperial College Healthcare NHS Trust, Charing Cross Hospital, Fulham Palace Road, London W6 8RF, UK; rweiler@doctors.org.uk
£1 million across the UK, and GPs have proved adept at reaching QOF targets. ${ }^{6}$ GPs are not trained to give lifestyle modification advice, but last year QOF included physical activity for the first time under a 'cardiovascular risk assessment and management' indicator. Specifically, 40-70\% of newly diagnosed hypertensive patients should be 'given lifestyle advice in the last 15 months for: increasing physical activity, smoking cessation, safe alcohol consumption and healthy diet.' Smoking and diet are already included elsewhere under $\mathrm{QOF}$, and the lack of emphasis on physical activity as an individual indicator provides mixed messages, negating its fundamental importance and rendering its promotion an afterthought. As things stand, QOF will not change in 2010/2011 because of unique circumstances relating to swine flu costs and implications. ${ }^{7}$

Nevertheless, evidence shows that even brief interventions (3-10 $\mathrm{min}$ ) or simple pedometer-based programmes delivered through health professionals can lead to substantial increases in patients' activity levels (by $\sim 30 \%$ ). ${ }^{8}$ Lawton et al have shown in a randomised controlled trial (RCT) that physical activity promotion can improve behaviours in general practice care when coordinated with exercise on referral, which is widely accessible in the UK. Regular intervention built on existing real, longstanding primary care relationships may have a significant impact and effect on patients. It seems illogical that physical activity interventions in primary care remain neglected and unrewarded at the expense of other 'recognised' risk factors, which are all symptoms of physical inactivity. Further objective research with greater consideration of methods and interventions with reliable outcome measures, which can be applied in real life, is needed.

\section{OLYMPIC LEGACY}

In 2012, the Olympic games will be hosted in London, and there has been the usual host city talk of the health benefits and a legacy strategy plan. ${ }^{10} 11$ One much hyped expected legacy has been to use the 'trickle-down effect' (also known as the 'demonstration effect'), an unsubstantiated expectation that publicity and Olympic medal successes will inspire the nation to increase physical activity levels. ${ }^{12-14}$

Leading British politicians have even claimed that the London 2012 Olympics will make the nation healthier and combat the obesity epidemic. ${ }^{12}$

Despite the lack of evidence, a staggering $£ 480$ million of government and lottery funds were originally earmarked for investment in grass roots sport (these funds have since been reported to have been significantly reduced to help pay for Olympic delivery with further budget cuts still predicted) with the intention of boosting sport participation in the 4 years preceding the 2012 games. ${ }^{15} 16$ Strategies aimed at promoting physical activity in the general population require close coordination and improvements in communication between the sports and health sectors, but in reality these two sectors compete for limited funds. Time is running out for plans to be coordinated and implemented.

\section{REASONS FOR LOW LEVELS OF PHYSICAL ACTIVITY PROMOTION AND UPTAKE}

To address these issues, we need to assess why physical activity promotion has been 'all talk,' even though a clear call to action was recognised almost three decades ago. ${ }^{17}$

First, current strategies for increasing physical activity levels may have been held back by an apparent lack of exercise medicine knowledge and training among healthcare professionals. ${ }^{18}$ Only 13\% of US medical schools include physical activity in their curriculum, and the reality is probably not much better in the UK. ${ }^{19}$ Curriculum changes are certainly required with dedicated time spent on the fundamentals of preventive medicine and exercise medicine, health promotion and lifestyle modification skills. Until these learning needs are addressed, GPs may need to involve and refer patients to suitably trained allied healthcare professionals and 'approved' fitness professionals to maximise the chances of successful behaviour change.

Second, research has shown that doctors who exercise themselves are more likely to promote physical activity to their patients. ${ }^{20}$ However, if physical activity levels are in reality as pandemically and dangerously low in healthcare professionals as the public, it is hardly surprising that physical activity promotion is neglected. Improved physical activity and health in NHS staff will generate considerable 
positive publicity for public health and prevention messages, will create numerous role models and has also been estimated to save the NHS £555 million a year in direct costs. ${ }^{21}$

Third, there has been minimal investment researching effective ways to increase physical activity in general practice and other contexts (eg, community, workplace, schools) and promote its numerous benefits. On the other hand, the pharmaceutical industry, for example, invests enormous amounts of funds on drugs research and marketing, on directly influencing medical practice in the form of consulting payments, research funding, sponsorship and gifts to professionals ${ }^{22} 23$ and perhaps on even influencing the results of drugs research. ${ }^{24}$

Fourth, reductionist medical and political doctrine ('target-culture') influences healthcare practitioners to a simplistic understanding of the causation of illness and neglects health behaviours (ie, the actual causes) in favour of surrogate risk markers. Invariably, the first-line treatments for all these symptoms of poor lifestyles are pharmacological, perhaps to a large extent for the reasons outlined above. Increased physical activity can reduce mortality by as much as smoking cessation, even in later life, and yet smoking cessation is institutionally endorsed, and physical activity promotion is not. ${ }^{25}$

Fifth, the design of physical activity interventions makes their interpretation problematic; even more so when applied to public health policy. Changes to deeply rooted sedentary habits are often attempted in short-term interventions. Long-term follow-up of real-life individualised GP intervention to patients within established relationships, where the intervention and management plan are autonomously agreed and followed up, is fundamental and too easily forgotten. ${ }^{26}$ Most of the numerous collateral benefits of physical activity go unmeasured, and control groups enabling RCT studies are unethical (ie, for controls to remain inactive for long periods given the known health risks). ${ }^{27}$

Despite these inherent evidence limitations, the NHS National Institute for Health and Clinical Excellence (NICE) recommends physical activity promotion in primary care based on cost-benefit analysis. ${ }^{28}$ Both NICE and the Department for Health consider brief physical activity intervention in primary care 'exceptional value for money'29 and may need to incentivise changes in practice rather than leave non-standardised initiatives, such as 'lets get moving,' optional.

\section{A FEW SIMPLE FIRST STEPS}

We propose that policymakers should simply introduce physical activity promotion into QOF at the earliest opportunity as its own individual indicator at an incomprehensibly modest cost close to $£ 1$ million $^{6}$ (when compared with the enormous annual physical inactivity cost of $£ 8.2$ billion in $2002,{ }^{1}$ which is likely to be much higher in 2010). This would quickly incorporate physical activity into computerised GP medical systems and motivate regular follow-up and national integration of physical activity promotion within primary care consultations. This could start with the introduction of the simple validated GP Physical Activity Questionnaire (GPPAQ) for patients aged 16-74 years without longstanding illness or disability. It can be completed in about 60 seconds without assistance and provides a simple, four-level Physical Activity Index of: active, moderately active, moderately inactive and inactive, which are correlated with cardiovascular disease risk and reflect the importance of a physical activity dose-response relationship (ie, more physical activity leads to greater health benefits). ${ }^{30}$

GPPAQ development started in 2002 and cost around $£ 82000$ (2003 values) to develop and validate, excluding staff costs. It is currently largely unused, confirmed by a recent survey of the March 2010 General Practice Research Database, Gold database of 9556849 patients, where only 660 patients $(0.007 \%)$ were found to have ever been coded for any of the GPPAQ read codes across 524 practices in the UK.

Introduction of GPPAQ will help identify those mostly in need (ie, $95 \%$ of the population $^{1}$ ) and raise awareness of the numerous health benefits of physical activity. It will set the ball rolling and ensure that the primary care workforce becomes more aware and better educated about the enormous benefits of physical activity.

In addition to these first steps, there are more options available to facilitate this process. GPs (and all other healthcare professionals) should receive comprehensive training on exercise medicine and behaviour change during undergraduate and postgraduate training. Already qualified healthcare professionals should be offered opportunities and incentives for professional training on lifestyle medicine and particularly physical activity, which is the single most important modality for prevention and management of most chronic disease.
Critics will debate the evidence base for such a health policy, but careful attention to methods and evaluation would make this strategy pioneering and economical national research, which should placate sceptics and help strengthen the evidence base of the future.

Given the significant associated mortality and morbidity, we propose that perhaps physical inactivity should also be considered for recognition as a disease in its own right.

These initiatives should all be introduced in conjunction with physical activity education among healthcare professionals, coordination of the sport, exercise and health sectors, collaboration with the existing fitness industry and the involvement (and employment) of NHS Sport \& Exercise Medicine specialists and Public Health \& Epidemiology specialists.

If these relatively cheap initiatives are not commenced prior to 2011, then the physical activity legacy of London 2012 may be limited to urban regeneration in the areas around the Olympic village, some cycle lanes and most likely several 'white elephant' buildings that will be largely unused in the medium to long term.

\section{CONCLUSION}

Given that physical inactivity has an adult population prevalence of $95 \%$, placing a huge strain and financial burden on our NHS, there is an imperative need to facilitate all these health service-related, societal and cultural changes so that physical activity is increased.

The evolution of exercise medicine has reached a critical crossroad in the UK. Can we afford to leave physical activity promotion in primary care as the "wouldbe-nice' preventive option, offered typically in the form of unstructured advice by inadequately trained professionals? Policymakers have an opportunity to address the current huge physical inactivity burden, make the most of the 2012 Olympic legacy and make the NHS a global leader in physical activity promotion.

Acknowledgements Thanks to M Cullen and L Creaney for their comments on the first draft of this paper. We would also like to thank the General Practice Research Database (GPRD) Research Team for performing the search of the March 2010 Gold database.

Competing interests None.

Provenance and peer review Not commissioned; externally peer reviewed.

Accepted 19 May 2010

Br J Sports Med 2010;44:912-914.

doi:10.1136/bjsm.2010.073726 


\section{REFERENCES}

1. Joint Health Surveys Unit (National Centre for Social Research and UCL Department of Epidemiology and Public Health). Health Survey for England - 2008: Physical Activity and Fitness. The NHS Information Centre, Leeds, UK, 2009. http:// www.ic.nhs.uk/pubs/hse08physicalactivity laccessed Jun 2010)

2. Troiano RP, Berrigan D, Dodd KW, et al. Physical activity in the United States measured by accelerometer. Med Sci Sports Exerc 2008:40:181-8.

3. Parrott S, Godfrey C. Economics of smoking cessation. BMJ 2004;328:947-9.

4. Balakrishnan R, Allender S, Scarborough P, et al. The burden of alcohol-related ill health in the United Kingdom. J Public Health (Oxf) 2009:31:366-73.

5. Blair SN. Physical inactivity: the biggest public health problem of the $21^{\text {st }}$ century. Br J Sports Med 2009;43:1-2.

6. Simon C. The quality and outcomes framework. InnovAiT 2008;1:206-13.

7. National Institute for Clinical Excellence. NICE Comment on 2010/11 Q0F Decision. http://www. nice.org.uk/aboutnice/qof/Indicators.jsp (accessed Jun 2010)

8. Marcus BH, Williams DM, Dubbert PM, et al. Physical activity intervention studies: what we know and what we need to know: a scientific statement from the American Heart Association Council on Nutrition, Physical Activity, and Metabolism (Subcommittee on Physical Activity); Council on Cardiovascular Disease in the Young; and the Interdisciplinary Working Group on Quality of Care and Outcomes Research. Circulation 2006;114:2739-52.

9. Lawton BA, Rose SB, Raina Elley C, et al. Exercise on prescription for women aged 40-74 recruited through primary care: two year randomised controlled trial. Br J Sports Med 2009;43:120-3.

10. Department of Health. London-The 2012 Olympic Bid-A Lasting Health Legacy. http://webarchive. nationalarchives.gov.uk/+/www.dh.gov.uk/en/ Publicationsandstatistics/Publications/AnnualReports/ Browsable/DH_5330236 (accessed Jun 2010).

11. Batt M. London 2012: Legacy A Position Paper from the Faculty of Sport and Exercise Medicine,
2009. http://www.fsem.co.uk/DesktopModules/ Documents/DocumentsView.aspx?tabID =0\&ltemID $=114641 \& \mathrm{Mld}=5288 \&$ wversion $=$ Staging.

12. Armstrong G, Stamatakis E, Cambell N. The sporting legacy of Olympic games and major sporting events. reality reconsidered. In: Roibas A, Stamatakis E, Black K, eds. Design for Sport. London: Gowr/Ashgate $2011 ; 9$

13. Weed M, Coren E, Fiore J, et al. A Systematic Review of the Evidence Base for Developing a Physical Activity and Health Legacy from the London 2012 Olympic and Paralympic Games. Department of Health and Centre for Sport, Physical Education and Activity Research (SPEAR), Canterbury Christ Church University. London, 2009. http://www.london.nhs.uk/ webfiles/Independent\%20inquiries/Developing\%20 physical\%20activity\%20and\%20health\%20legacy\% 20-\%20full\%20report.pdf (accessed Jun 2010).

14. McCartney G, Thomas S, Thomson $\mathrm{H}$, et al. The health and socioeconomic impacts of major multisport events: systematic review (1978-2008). BMJ 2010;340:c2369

15. Sport England. Sport England, press release, 11 March 2009. http://www.sportengland.org/media centre/press releases/building partnerships.aspx (accessed Jun 2010)

16. Gibson 0, Higgins C. The Guardian, 25 May 2010. http://www.guardian.co.uk/politics/2010/may/25/ arts-sport-facing-budget-cuts (accessed Jun 2010).

17. MacAuley DC. Why not sports medicine in general practice? J R Coll Gen Pract 1982;32:700-1.

18. Pate RR, Pratt M, Blair SN, et al. Physical activity and public health. A recommendation from the Centers for Disease Control and Prevention and the American College of Sports Medicine. JAMA 1995:273:402-7.

19. Garry JP, Diamond JJ, Whitley TW. Physical activity curricula in medical schools. Acad Med 2002:77:818-20.

20. McKenna J, Naylor PJ, McDowell N. Barriers to physical activity promotion by general practitioners and practice nurses. Br J Sports Med 1998;32:242-7.

21. NHS Health and Well-being Review. Interim Report. The Boorman Review, 2009. http://www.
nhshealthandwellbeing.org/pdfs/NHS\%2OHWB\%20 Review\%20Interim\%20Report\%20190809.pdf (accessed Jun 2010)

22. Licurse A, Barber E, Joffe S, et al. The impact of disclosing financial ties in research and clinical care: a systematic review. Arch Intern Med 2010;170:675-82

23. Campbell EG. Public disclosure of conflicts of interest: moving the policy debate forward. Arch Intern Med 2010;170:667.

24. Als-Nielsen B, Chen W, Gluud C, et al. Association of funding and conclusions in randomized drug trials: a reflection of treatment effect or adverse events? JAMA 2003:290:921-8.

25. Byberg L, Melhus H, Gedeborg R, et al. Total mortality after changes in leisure time physical activity in 50 year old men: 35 year follow-up of population based cohort. Br J Sports Med 2009;43:482.

26. Puska P. Commentary: Physical activity promotion in primary care. Int J Epidemiol 2002;31:815-17

27. Stamatakis $\mathbf{E}$, Weiler R. Prevention of cardiovascular disease: why do we neglect the most potent intervention? Heart 2010;96:261-2.

28. National Institute for Clinical Excellence. NICE Public Health Intervention Guidance No. 2. Fou Commonly Used Methods to Increase Physical Activity: Brief Interventions in Primary Care, Exercise Referral Schemes, Pedometers and Communitybased Exercise Programmes for Walking and Cycling, 2006. http://guidance.nice.org.uk/PH2 laccessed Jun 2010).

29. Let's Get Moving. Commissioning Guidance. A New Physical Activity Care Pathway for the NHS Department of Health, 2009:28 http://www.dh.gov. uk/prod_consum_dh/groups/dh_digitalassets/ documents/digitalasset/dh 105944.pdf (accessed Jun 2010).

30. The General Practice Physical Activity Questionnaire (GPPAO). A Screening Tool to Assess Adult Physical Activity Levels, Within Primary Care. Department of Health. http://www.dh.gov.uk/prod consum dh/ groups/dh_digitalassets/documents/digitalasset/ dh 101579.pdf (accessed Jun 2010). 